\title{
The Enantioselective Synthesis of Marmelo Oxides A and B and the Assignment of the Absolute Configurations of Marmelo Oxides
}

\author{
Yoshihiro Nishida, Yuko Fukushima, Hiroshi Ohrui \\ and Hiroshi Meguro \\ Department of Food Chemistry, Faculty of Agriculture, \\ Tohoku University, Amamiyamachi-Tsutsumidori, Sendai 980, Japan
}

Received October 6, 1983

\begin{abstract}
(+)-Marmelo oxide $\mathbf{A}$ and (-)-marmelo oxide $\mathbf{B}$ were stereoselectively synthesized from Dglutamic acid via (-)-marmelo lactones $\mathbf{A}$ and $\mathbf{B}$. The absolute configurations of marmleo oxides were thus determined to be the (+)-oxide $\mathbf{A}$ having the $(2 R, 4 R)$ and $(+)$-oxide $\mathrm{B}$ having $(2 S, 4 R)$ configurations.
\end{abstract}

Marmelo oxides $\mathbf{A}$ and $\mathbf{B}$ have been isolated from the fruit of quince (Cydonia oblonga MILL, marmelo) by Tsuneya et al., together with marmelo lactones $\mathbf{A}$ and $\mathbf{B}^{1,2)}$ It was reported that the two oxides were responsible for the strong characteristic flavor of the fruit, which is sometimes used in the food industry. $\left.{ }^{2}\right)$ They were assigned ${ }^{2)}$ as 2,4-trans and 2,4-cis stereoisomers of 4-methyl-2-(E-3-methyl-1,3butadienyl) oxolane with a novel monoterpene skeleton related to Rose oxides ${ }^{3)}$ or Lavender pyrans. ${ }^{4)}$ However, the configurations of their chiral centers at $\mathrm{C} 2$ and $\mathrm{C} 4$ have not yet been reported. Previously, we reported the assignment of the absolute configurations of marmelo lactones $\mathbf{A}$ and $\mathbf{B}$, based upon their stereoselective syntheses. ${ }^{5)}$ Here, similar attempts have been directed to the oxides.

In our preliminary communication, ${ }^{7)}$ the stereoselective syntheses of (+)-marmelo oxide $\mathbf{A}$ and (-)-oxide $\mathbf{B}$ and their absolute configurations were described. In this paper, we discuss the results in more detail.

The key compounds, (+)-marmelo lactones $\mathbf{A}$ and $\mathbf{B}$, had already been synthesized from erythro- and threo- $\gamma$-methyl-L-glutamic acid. ${ }^{5}$ Here, more facile syntheses of the (-)-lactones were carried out from D-glutamic acid (Fig. 1).

D-Glutamic acid was converted to the al- dehyde (I) according to the established method. ${ }^{5,8)}$ The Wittig reaction of $\mathbf{I}$ with triphenylphosphonium methallylid ${ }^{12)}$ gave a mixture of II and its $5 Z$ isomer $\left(\mathbf{I I}^{\prime}\right)\left(\mathbf{I I} / \mathbf{I I}^{\prime}=\right.$ $5 / 4, G C$ analysis), from which II was isolated through silica gel column chromatography in a $30 \sim 40 \%$ yield from I $\left(\right.$ II, $[\alpha]_{\mathrm{D}}^{23}-49.4^{\circ}$ in methanol). The $5 Z$ and $5 E$ isomers were readily characterized by the $J_{\mathrm{H} 5, \mathrm{H} 6}$ values of their ${ }^{1} \mathrm{H}$-NMR because the $5 Z$ isomer had a smaller value $(9.52 \mathrm{~Hz})$ than the $5 E$ isomer $(15.6 \mathrm{~Hz})^{6}{ }^{6}$

Methylation $^{9)}$ of II with lithium diisopropylamide (LDA) and methyl iodide (MeI) proceeded stereoselectively to give IIIA and IIIB in a ratio of $6: 1$ (HPLC analysis ${ }^{5)}$ ). They were separated by silica gel column chromatography (IIIA : $[\alpha]_{\mathrm{D}}^{23}-74.9^{\circ}$ in methanol, lit. ${ }^{2)}$ $+103^{\circ}$ for $(+)$-IIIA). The kinetic protonation of the enolate of IIIA with the method of Takano et al. ${ }^{9,10)}$ gave a mixture of IIIA and IIIB ( $1: 5)$, from which IIIB was isolated as a syrup by column chromatography on silica gel (IIIB : $[\alpha]_{\mathrm{D}}^{23}-18.9^{\circ}$ in methanol, lit. ${ }^{2)}-20^{\circ}$ ). The lower optical rotations of IIIA and IIIB suggested partial epimerization at the $\mathrm{C} 4$ position throughout these procedures. However, this was not a problem in this study because the stereochemistry of IIIA and IIIB had already been established. ${ }^{5,6)}$ The reduction of 


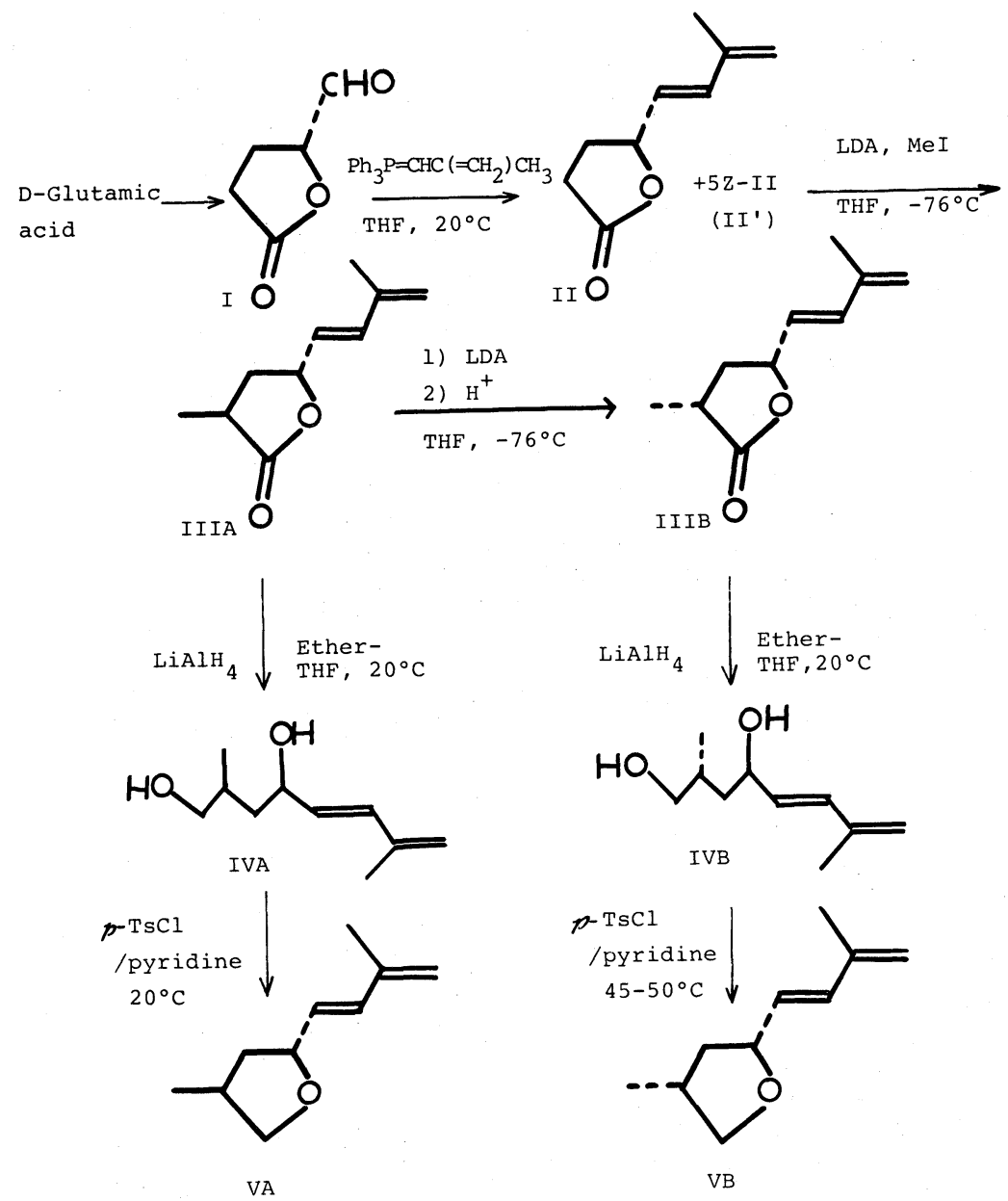

FIG. 1. Syntheses of Marmelo Oxides A and B from D-Glutamic Acid via (-)-Marmelo Lactones A and B.

IIIA with lithium aluminium hydride $\left(\mathrm{LiAlH}_{4}\right)$ gave the diol (IVA) in a $90 \%$ yield, which was cyclized with an equimolar amount of $p$ toluenesulfonyl chloride $(p-\mathrm{TsCl})$ in pyridine to give the (-)-2,4-trans oxide (VA) in a $60 \%$ yield (VA : $[\alpha]_{\mathrm{D}}^{23}-33.4^{\circ}$ in ethyl ether).

In a similar way, the 2,4-cis oxide (VB) was synthesized from IIIB. However, the cyclization procedure needed a prolonged reaction time and high temperature and caused partial epimerization at $\mathrm{C} 2$ by approximately $15 \%$, (HPLC and ${ }^{1} \mathrm{H}-\mathrm{NMR}$ analysis) which might be attributed to the cis 1,3-substituents on the oxolane ring. The product containing approximately $15 \%$ of $(+)$-VA was used for spectroscopic studies without further purification. The NMR data of VB were obtained by subtracting those of VA and the $[\alpha]_{\mathrm{D}}$ value was calibrated by taking account of the $15 \%(+)$ VA, VB : $[\alpha]_{D}^{23}=+23.5^{\circ}$ (ethyl ether).

The ${ }^{1} \mathrm{H}-\mathrm{NMR}$ data of VA and VB agreed with those of the reported marmelo oxides $\mathbf{B}$ and $\mathbf{A}$, respectively. ${ }^{2)}$ Here, the two oxides were differentiated from each other by the chemical shift of one of the methylene protons at $\mathrm{C} 3$; the 2,4-trans oxide (VA) gave $1.6 \sim 2.0 \mathrm{ppm}$ (lit. ${ }^{2)} 1.55 \sim 1.85 \mathrm{ppm}$ for oxide B), while the 2,4-cis oxide (VB) gave $1.1 \sim 1.5 \mathrm{ppm}$ (lit. ${ }^{2)} 1.15 \sim 1.35 \mathrm{ppm}$ for oxide A). For a determination of the configuration at $C 2$, the sign of $[\alpha]_{D}$ and the $C D$ results should be treated cautiously because VB showed a positive rotation in a longer wavelength region $\left([\mathrm{M}]_{589}=+36^{\circ}, \quad[\mathrm{M}]_{400}=+90^{\circ}, \quad[\mathrm{M}]_{300}=\right.$ 


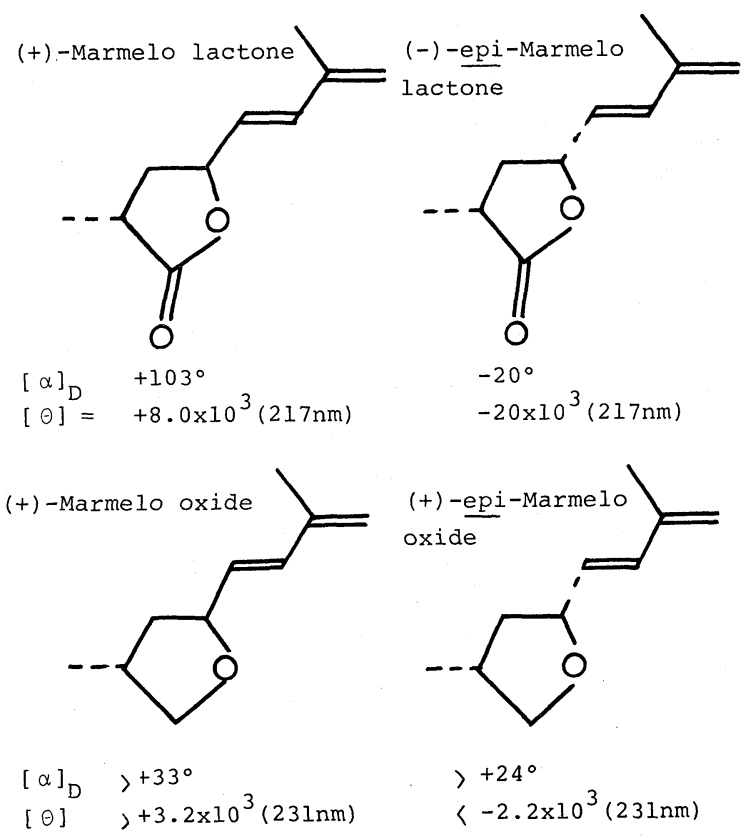

Fig. 2. Absolute Configurations of Marmelo Lactones and Oxides.

$\left.+158^{\circ}\right)$ in contrast with its negative Cotton effect at $231 \mathrm{~nm}$ (due to $\pi \rightarrow \pi^{*}$ of the conjugated double bond) to reflect its $2 R$ configuration (Fig. 2).

Since the reactions from IIIA and IIIB were expected to proceed with retention of the configurations, the absolute configurations of $(+)$ - and (-)-marmelo oxides $\mathbf{A}$ and $\mathbf{B}$ were established as the (+)-oxide A having $(2 R, 4 R)$ and ( + )-oxide $\mathbf{B}$ having $(2 S, 4 R)$ configurations. Although the optical rotations of the natural oxides have not yet been reported, their absolute configurations can be determined from the sign of their optical rotations.

The original nomenclature ${ }^{2)}$ of the oxide seems to be inconvenient or confusing since they referred to the 2,4-trans oxide as oxide $\mathbf{B}$ and the 2,4-cis oxide as oxide $\mathbf{A}$, in spite of the fact that the 2,4-trans lactone is called marmelo lactone $\mathbf{A}$ and the 2,4-cis lactone is lactone B. ${ }^{1,2)}$ Therefore, we propose that 2,4trans marmelo oxide and 2,4-cis oxide should be better called marmelo oxide and epimarmelo oxide, respectively. In the same manner, 2,4-trans marmelo lactone would be marmelo lactone and 2,4-cis lactone would be epi- marmelo lactone, as illustrated in Fig. 2.

In conclusion, (-)-marmelo oxide $((-)$ oxide B) and (+)-epi-marmelo oxide $((+)$ oxide A) were stereoselectively synthesized from D-glutamic acid via ( -$)$-marmelo lactone $((-))$-lactone $\mathbf{A})$ and (-)-epi-marmelo lactone ((-)-marmelo lactone B), respectively. Thus, the absolute configurations of all the possible diastereomers of the oxides were established synthetically.

\section{EXPERIMENTAL}

Melting points and boiling points were uncorrected. IR spectra were recorded on a Jasco A-202 spectrometer and NMR spectra on a JEOL JNM-FX 100 Fourier transform spectrometer in $\mathrm{CDCl}_{3}$ with TMS as an internal standard. Direct Mass spectra were recorded on a HITACHI M52 spectometer and CD spectra on a Dichrograph Mark IIIJ. Optical rotations were measured on a Jasco ORD/UV5. Kiesel gel $60 \mathrm{GF}_{254}$ (Merck) was used for both analytical and preparative TLC. HPLC was performed with a Jasco TRIROTAR equipped with a Jasco UV/DEC-100II.

(4R, 5E)-7-Methyl-5,7-octadien-4-olide (II). To the stirred suspension of $\mathrm{Ph}_{3} \mathrm{P} \stackrel{+}{\mathrm{C}} \mathrm{H}_{2} \mathrm{C}\left(=\mathrm{CH}_{2}\right) \mathrm{CH}_{3} \mathrm{Cl}^{-12)}(4 \mathrm{~g}$, $10 \mathrm{mmol})$ in dry THF $(20 \mathrm{ml})$ was added dropwise $n$-BuLi 
$(15 \%$ in $n$-hexane $(\mathrm{w} / \mathrm{w}), 7 \mathrm{ml})$ under $\mathrm{N}_{2}$. The mixture turned red immediately and was left for $40 \mathrm{~min}$ at room temperature under $\mathrm{N}_{2}$. To the vigorously stirred solution was added the crude aldehyde (I) $(800 \mathrm{mg}, 7 \mathrm{mmol})$ during a period of $10 \mathrm{~min}$ at $20^{\circ} \mathrm{C}$. After being maintained for $3 \mathrm{hr}$ at room temperature, the reaction mixture was poured into a sat. $\mathrm{NaCl}$ solution and extracted with ethyl ether $(15 \mathrm{ml} \times 3)$. The aqueous layer was acidified with dil. $\mathrm{HCl}$, stirred for an hour and then extracted with ethyl ether $(10 \mathrm{ml} \times 3)$. The ethereal extracts were combined and washed with sat. $\mathrm{NaCl}$ solution and dried over $\mathrm{Na}_{2} \mathrm{SO}_{4}$. After evaporating the solvents, the residue was chromatographed on a silica gel column $(2.5 \mathrm{~cm} \phi \times 60 \mathrm{~cm})$ and eluted with a mixture of petroleum ether-ethyl ether $(6: 1$, $\mathrm{v} / \mathrm{v})$. The fractions containing the faster moving compound $(R f=0.5$, petroleum ether-ethyl ether $=1: 2)$ were collected and evaporated in vacuo to give a $5 Z$ isomer of II (II'), $180 \mathrm{mg}(17 \%)$, creamy flavor oil, $[\alpha]_{\mathrm{D}}^{23}+52.6^{\circ}$ $\left(c=0.2, \mathrm{CH}_{3} \mathrm{OH}\right), \mathrm{MS} m / z: 152\left(\mathrm{M}^{+}\right), 136,124,110$, 109, 95. ${ }^{13} \mathrm{C}-\mathrm{NMR}: 22.9,29.1,29.8,76.9,117.2,128.1$, 136.1, 140.6, 177.5. ${ }^{1} \mathrm{H}-\mathrm{NMR}: 1.90\left(3 \mathrm{H}, \mathrm{s},-\mathrm{CH}_{3}\right), 4.90$ $(1 \mathrm{H}, \mathrm{s}, \mathrm{H} 8 \mathrm{a}), 5.10(1 \mathrm{H}, \mathrm{s}, \mathrm{H} 8 \mathrm{~b}), 5.30\left(1 \mathrm{H}, \mathrm{dd}, J_{\mathrm{H} 5, \mathrm{H} 6}=\right.$ $9.52 \mathrm{~Hz}, \mathrm{H} 5), 6.14(1 \mathrm{H}, \mathrm{d}, J=9.52 \mathrm{~Hz}, \mathrm{H} 6)$.

The slower moving fractions $(R f=0.4)$ gave a waxy odor syrup of II, $220 \mathrm{mg}(21 \%),[\alpha]_{\mathrm{D}}^{23}+54.3^{\circ}(c=0.2$, $\left.\mathrm{CH}_{3} \mathrm{OH}\right), \mathrm{MS} m / z: 152\left(\mathrm{M}^{+}\right), 136,124,110,109,97,95$, 85. ${ }^{1} \mathrm{H}-\mathrm{NMR}$ : $1.85\left(3 \mathrm{H}, \mathrm{s},-\mathrm{CH}_{3}\right), 5.04(2 \mathrm{H}$, broad s, H8a and $\mathrm{H} 8 \mathrm{~b}), 5.63(1 \mathrm{H}, \mathrm{dd}, J=6.1$ and $15.6 \mathrm{~Hz}, \mathrm{H} 5), 6.38$ $(1 \mathrm{H}, \mathrm{d}, J=15.6 \mathrm{~Hz}, \mathrm{H} 6) .{ }^{13} \mathrm{C}-\mathrm{NMR}: 18.4,28.6,29.0,80.7$, $118.7,126.5,135.8,140.7,176.8$.

$(2 S, 4 R, 5 E)-2,7-D i m e t h y l-5,7-o c t a d i e n-4-o l i d e \quad((-)-$ marmelo lactone), (IIIA). To a cooled solution $\left(-76^{\circ} \mathrm{C}\right.$, dry-ice/acetone) of diisopropylamine $(0.18 \mathrm{ml})$ in $\mathrm{THF}$ ( $3 \mathrm{ml}$, dried over $\mathrm{Na}$ ) was added dropwise $n$-BuLi $(15 \%$ in $n$-hexane, $0.85 \mathrm{ml}, \mathrm{w} / \mathrm{w})$ to give an LDA solution (1.2 mmol). After stirring for $30 \mathrm{~min}$ at $-76^{\circ} \mathrm{C}$ under $\mathrm{N}_{2}$, IIA $(150 \mathrm{mg}, 1 \mathrm{mmol}$ in $1 \mathrm{ml}$ of THF) was added dropwise over $10 \mathrm{~min}$ with a glass syringe and the mixture was kept for $10 \mathrm{~min}$ at $-76^{\circ} \mathrm{C}$ under $\mathrm{N}_{2}$. To the solution was added in one portion MeI $(0.08 \mathrm{ml}, 1.2 \mathrm{mmol}$ in $1 \mathrm{ml}$ of THF) with a glass syringe. The temperature of the solution was gradually raised to $-30^{\circ} \mathrm{C}$ over $2 \mathrm{hr}$. To the solution was added $10 \% \mathrm{HCl}(10 \mathrm{ml})$ and the solution was kept at room temperature for $2 \mathrm{hr}$ before being poured into a sat. $\mathrm{NaCl}$ solution. The $\mathrm{NaCl}$ solution was extracted with ethyl ether $(10 \mathrm{ml} \times 3)$ and the ethereal extracts were combined and dried over $\mathrm{MgSO}_{4}$. After removing the solvent in vacuo, the residue was mounted on a silica gel column $(2.5 \mathrm{~cm} \phi \times$ $60 \mathrm{~cm})$ and eluted with $n$-hexane-ethyl acetate $(6: 1, \mathrm{v} / \mathrm{v})$. The fractions containing a fast moving compound $(R f=$ $0.33, n$-hexane-ethyl acetate $=4: 1$ ) were collected and concentrated to give a sweet flavor syrup of IIIA, $100 \mathrm{mg}$ (61\% yield from IIA), $[\alpha]_{D}^{23}-74.9^{\circ}\left(c=0.2, \mathrm{CH}_{3} \mathrm{OH}\right)$. The ${ }^{1} \mathrm{H}-\mathrm{NMR},{ }^{13} \mathrm{C}-\mathrm{NMR}$ and mass spectral data agreed with those of the authentic sample. ${ }^{5,7)}$ The slower moving fractions gave a syrup of IIIB, $14 \mathrm{mg}(9 \%)$ with a sweet flavor similar to IIIA, $[\alpha]_{\mathrm{D}}^{23}-19.0^{\circ}\left(c=0.2, \mathrm{CH}_{3} \mathrm{OH}\right)$. The spectral data agreed with those of the authentic material. ${ }^{5,7)}$

(2R, 4R, 5E)-2,7-Dimethyl-5,7-octadien-4-olide ((-)-epimarmelo lactone), (IIIB). To the LDA solution (1.2 $\mathrm{mmol}$ in THF at $-76^{\circ} \mathrm{C}$ ) was added dropwise IIIA $(150 \mathrm{mg}$ in $1 \mathrm{ml}$ of THF) and the solution was stirred for $20 \mathrm{~min}$ at $-76^{\circ} \mathrm{C}$ under $\mathrm{N}_{2}$. A sat. $\mathrm{Na}_{2} \mathrm{SO}_{4}$ solution $(10 \mathrm{ml})$ was added rapidly and the mixture was warmed to room temperature before being poured into a sat. $\mathrm{NaCl}$ solution. The solution was extracted with ethyl ether $(10 \mathrm{ml} \times 3)$. The aqueous layer was acidified with dil. $\mathrm{HCl}$, stirred for $30 \mathrm{~min}$ at room temperature and then extracted with ethyl ether $(10 \mathrm{ml} \times 3)$. The ethereal extracts were combined, washed with a sat. $\mathrm{NaCl}$ solution and dried over $\mathrm{Na}_{2} \mathrm{SO}_{4}$. After removing the solvent in vacuo, the residue gave a mixture of IIIA and IIIB ( $1: 5)$ as a syrup (130 mg, 87\%), which was mounted on a silica gel column and eluted with $n$-hexane-ethyl acetate $(6: 1, \mathrm{v} / \mathrm{v})$. The slower moving eluents were collected to give a syrup of IIIB, $83 \mathrm{mg} \mathrm{(53 \% ),}$ $[\alpha]_{\mathrm{D}}^{23}-18.9^{\circ}\left(c=0.2, \mathrm{CH}_{3} \mathrm{OH}\right)$. The ${ }^{1} \mathrm{H}-\mathrm{NMR},{ }^{13} \mathrm{C}-\mathrm{NMR}$ and mass spectral data agreed with those of the authentic materials. ${ }^{5,7)}$

(2S, 4R, 5E)-2,7-Dimethyl-5,7-octadiene-1,4-diol (IVA). To the suspension of $\mathrm{LiA}_{1} \mathrm{H}_{4}(91 \mathrm{mg}, 2.4 \mathrm{mmol})$ in ethyl ether $(20 \mathrm{ml})$ was added dropwise IIIA $(200 \mathrm{mg}, 1.2$ $\mathrm{mmol}$ in $10 \mathrm{ml}$ of THF) over $10 \mathrm{~min}$ at room temperature. After the mixture had been stirred for an hour, water saturated with ethyl ether $(15 \mathrm{ml}$ of water and $1 \mathrm{ml}$ of ethyl ether) was added dropwise over $30 \mathrm{~min}$. The mixture was vigorously stirred for $3 \mathrm{hr}$ and concentrated in vacuo. The residue was eluted with hot ethanol and the eluent concentrated to give a crude syrup of IVA, $200 \mathrm{mg}$ (98\% yield). The syrup was purified by a silica gel column eluted with benzene-ethyl acetate $(4: 1, \mathrm{v} / \mathrm{v})$. IVA: syrup, $[\alpha]_{\mathrm{D}}^{23}-12.7^{\circ}\left(c=0.2, \mathrm{CH}_{3} \mathrm{OH}\right),[\alpha]_{400}^{23}-40.7^{\circ}$. ${ }^{13} \mathrm{C}-\mathrm{NMR} \quad \delta_{\mathrm{CD}_{3} \mathrm{OD}}^{\mathrm{TMS}}: 17.6,18.8,33.5,42.3,68.2,71.7$, $116.7,133.9,134.0,143.0 .{ }^{1} \mathrm{H}-\mathrm{NMR} \delta_{\mathrm{CD}_{3} \mathrm{OD}}^{\mathrm{TMS}}: 0.93(3 \mathrm{H}$, d), $1.31 \sim 1.83(3 \mathrm{H}, \mathrm{m}), 1.84(3 \mathrm{H}, \mathrm{s}), 3.31 \sim 3.49(2 \mathrm{H}$, $\mathrm{m}), 4.11 \sim 4.30(1 \mathrm{H}, \mathrm{m}), 4.96(2 \mathrm{H}, \mathrm{s}), 5.63(1 \mathrm{H}, \mathrm{dd}), 6.32$ (1H, d).

(2R, 4R, 5E)-2,7-Dimethyl-5,7-octadiene-1,4-diol (IVB). In a similar manner to that described for the synthesis of IVA, IIIB $(100 \mathrm{mg})$ yielded $90 \mathrm{mg}$ of a viscous syrup of IVB, $[\alpha]_{\mathrm{D}}^{23}-0.08^{\circ}\left(c=0.15, \mathrm{CH}_{3} \mathrm{OH}\right),[\alpha]_{400}-7.7^{\circ} .{ }^{13} \mathrm{C}-$ NMR $\delta_{\mathrm{CD}_{3} \mathrm{OD}}^{\mathrm{TMS}}: 17.3,18.8,33.8,42.7,68.8,71.4,116.6$, $134.4,143.0 .{ }^{1} \mathrm{H}-\mathrm{NMR} \delta_{\mathrm{CD}_{3} \mathrm{OD}}^{\mathrm{TMS}}: 0.95(3 \mathrm{H}, \mathrm{d}), 1.11 \sim 1.40$ $(1 \mathrm{H}, \mathrm{m}), 1.51 \sim 1.80(2 \mathrm{H}, \mathrm{m}), 1.84(3 \mathrm{H}, \mathrm{s}), 3.30 \sim 3.41(2 \mathrm{H}$, m), $4.08 \sim 4.31(1 \mathrm{H}, \mathrm{m}), 4.95(2 \mathrm{H}, \mathrm{s}), 5.67(1 \mathrm{H}, \mathrm{dd}), 6.32$ (1H, d).

$(2 R, 4 S)-4-M e t h y l-2-((E)-3-m e t h y l-1,3-b u t a d i e n y l)$ oxolane $((-)$-marmelo oxide $)(V A) . \quad \rho$-Toluenesulfonyl chloride $\left(120 \mathrm{mg}, 6.3 \mathrm{mmol}\right.$ in $3 \mathrm{ml}$ of $\left.\mathrm{CHCl}_{3}\right)$ was added 
dropwise to a stirred and ice-cooled solution of IVA $(100 \mathrm{mg}, 5.9 \mathrm{mmol})$ in dry pyridine $(12 \mathrm{ml})$. The reaction mixture was stirred for $2 \mathrm{hr}$ below $4^{\circ} \mathrm{C}$ and then for $12 \mathrm{hr}$ at room temperature, while the reaction was checked with a TLC (petroleum ether-ethyl ether $=2: 1, \mathbf{V A}: R f=0.7$ $\left(\mathrm{I}_{2}\right.$ or $\mathrm{KMnO}_{4}$ positive)). The reaction mixture was poured into the ice-cooled water and extracted with ethyl ether $(15 \mathrm{ml} \times 3)$. The ethereal extracts were combined and washed with dil. $\mathrm{HCl}$ and sat. $\mathrm{NaCl}$ solution to remove the pyridine. After drying over $\mathrm{MgSO}_{4}$, the solvent was removed under a reduced pressure to give a colorless oil of VA, $60 \mathrm{mg}(67 \%$ yield $)$. This crude VA was purified by preparative TLC developed with petroleum ether-ethyl ether $(4: 1, \mathrm{v} / \mathrm{v})$ to give $56 \mathrm{mg}(56 \%)$ of a fruity flavored oil of VA: $[\alpha]_{\mathrm{D}}^{23}-33.4^{\circ}(c=0.18$, ethyl ether $)$. MS $m / z: 152$ $\left(\mathrm{M}^{+}\right), 137\left(\mathrm{M}^{+}-\mathrm{CH}_{3}\right), 96,95,93,81,69,68,67,55,41$. ${ }^{13}$ C-NMR : $17.8,18.6,33.4,40.6,75.2,79.1,116.5,130.8$, 133.3, 141.5. ${ }^{1} \mathrm{H}-\mathrm{NMR}: 1.05(3 \mathrm{H}, \mathrm{d}), 1.84(3 \mathrm{H}, \mathrm{s})$, $1.62 \sim 2.0(2 \mathrm{H}, \mathrm{m}), 2.10 \sim 2.61(1 \mathrm{H}, \mathrm{m}), 3.34(1 \mathrm{H}, \mathrm{dd}), 4.04$ $(1 \mathrm{H}, \mathrm{dd}), 4.49(1 \mathrm{H}, \mathrm{dd}), 4.96(2 \mathrm{H}, \mathrm{s}), 5.63(1 \mathrm{H}, \mathrm{dd}), 6.30$ $(1 \mathrm{H}, \mathrm{d})$.

$(2 R, 4 R)-4-M e t h y l-2-((E)-3-m e t h y l-1,3-$ butadienyl) oxolane $((+)$-epi-marmelo oxide $)(V B)$. Similarly to the preparation of VA, $100 \mathrm{mg}$ of IVB afforded a fruity oil of VB $(+15 \%(+)-\mathbf{V A}), 50 \mathrm{mg}$ in a $56 \%$ yield. Here, the reaction mixture was first kept at $4^{\circ} \mathrm{C}$ for $2 \mathrm{hr}$ and then at $45 \sim 50^{\circ} \mathrm{C}$ for $12 \mathrm{hr}$ to complete the cyclization. The spectral data of VB were obtained by taking account of the $15 \%(+)$-VA. VB: $[\alpha]_{\mathrm{D}}^{23}+23.5^{\circ}(c=0.15$, ethyl ether $)$ MS $m / z: 152$ $\left(\mathrm{M}^{+}\right), 137\left(\mathrm{M}^{+}-\mathrm{CH}_{3}\right), 96,95,93,81,79,69,67,55,41$. ${ }^{13} \mathrm{C}-\mathrm{NMR}: 17.6,18.6,34.8,41.8,74.9,80.6,116.5,130.7$,
133.6, 141.5. ${ }^{1} \mathrm{H}-\mathrm{NMR}: 1.06(3 \mathrm{H}, \mathrm{d}), 1.10 \sim 1.50(1 \mathrm{H}, \mathrm{m})$, $1.85(3 \mathrm{H}, \mathrm{s}), 2.0 \sim 2.59(2 \mathrm{H}, \mathrm{m}), 3.41(1 \mathrm{H}, \mathrm{dd}), 3.95(1 \mathrm{H}$, dd), $4.21 \sim 4.59(1 \mathrm{H}, \mathrm{m}), 4.96(2 \mathrm{H}, \mathrm{s}), 5.67(1 \mathrm{H}, \mathrm{dd}), 6.31$ $(1 \mathrm{H}, \mathrm{d})$.

\section{REFERENCES}

1) T. Tsuneya, M. Ishihara, H. Shiota and M. Shiga, Agric. Biol. Chem., 44, 957 (1980).

2) H. Shiota, M. Ishihara, T. Tsuneya and M. Shiga, Abstracts of Papers, 24th TEAC Symposium, 1980, p. 17; ibid., 1980, p. 95; ibid., 25th TEAC Symposium, 1981, p. 59.

3) C. F. Seidel and M. Stoll, Helv. Chim. Acta, 42, 1830 (1959).

4) Y. R. Naves, D. Lamparsky and P. Ochsner, Bull. Soc. Chim. Fr., 645 (1961).

5) Y. Nishida, H. Ohrui and H. Meguro, Agric. Biol. Chem., 47, 2123 (1983); ibid., 48, 1211 (1984).

6) Y. Nishida, T. Konno, H. Ohrui and H. Meguro, Agric. Biol. Chem., 47, 2683 (1983).

7) Y. Nishida, H. Ohrui and H. Meguro, Agric. Biol. Chem., 47, 2969 (1983).

8) R. E. Doolittle, J. H. Tumlinson, A. T. Proveaux and R. R. Heath, J. Chem. Ecol., 6, 473 (1980).

9) S. Takano, N. Tamura and K. Ogasawara, J. Chem. Soc., Chem. Commun., 1155 (1981).

10) S. Takano, W. Uchida, S. Hatakeyama and K. Ogasawara, Chem. Lett., 733 (1982).

11) J. Wolinski, B. Chollor and M. D. Baird, J. Am. Chem. Soc., 84, 2775 (1962). 